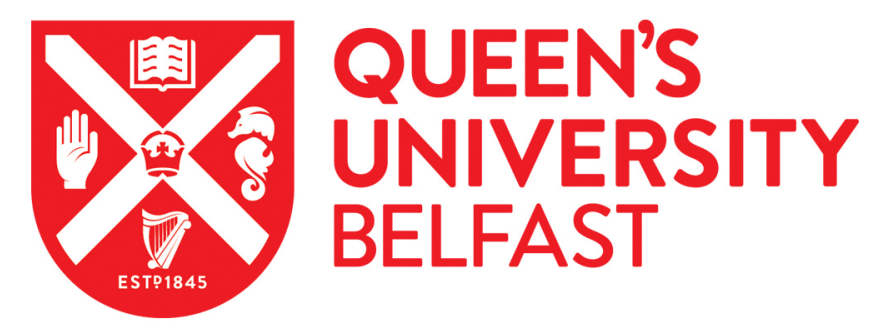

\title{
Behavior analytic interventions for children with autism: Policy and practice in the United Kingdom and China
}

Liao, Y., Dillenburger, K., \& Hu , X. (2021). Behavior analytic interventions for children with autism: Policy and practice in the United Kingdom and China. Autism. https://doi.org/10.1177/13623613211020976

Published in:

Autism

Document Version:

Peer reviewed version

Queen's University Belfast - Research Portal:

Link to publication record in Queen's University Belfast Research Portal

Publisher rights

Copyright 2021, the Authors.

This work is made available online in accordance with the publisher's policies. Please refer to any applicable terms of use of the publisher.

\section{General rights}

Copyright for the publications made accessible via the Queen's University Belfast Research Portal is retained by the author(s) and / or other copyright owners and it is a condition of accessing these publications that users recognise and abide by the legal requirements associated with these rights.

Take down policy

The Research Portal is Queen's institutional repository that provides access to Queen's research output. Every effort has been made to ensure that content in the Research Portal does not infringe any person's rights, or applicable UK laws. If you discover content in the Research Portal that you believe breaches copyright or violates any law, please contact openaccess@qub.ac.uk. 


\title{
Behavior Analytic Interventions for Children with Autism: Policy and practice in the United Kingdom and China
}

\author{
Yini Liao ${ }^{1}$, Karola Dillenburger ${ }^{2}, \&$ Xiaoyi $\mathrm{Hu}^{1}$ \\ ${ }^{1}$ Department of Psychology, Sun Yat-sen University, Guangzhou, China \\ ${ }^{2}$ Centre for Behaviour Analysis, Queens University Belfast
}

Accepted for publication (2021) Autism: International Journal of Research and Practice

\begin{abstract}
This study explored the experiences of professionals and parents from the United Kingdom (UK) and China of autism-relevant policies, school involvement, and Applied Behavior Analysis (ABA)-based interventions. Semistructured interviews were conducted involving 36 parents and professionals (18 from the UK and 18 from China) and direct behavioral observations were carried out of five parents and three professionals. Four subthemes emerged in the thematic analysis: (1) Chinese public policy about children with autism favored younger children and was more inclined to fund those living in poor conditions; (2) Chinese parents faced challenges around inclusive education and accessing high-quality services, and there was a social stigma attached to autism in China; (3) the evidence-based approach of ABA-based intervention was not widely endorsed by healthcare or educational systems and participants reported a limited awareness of early intensive behavior intervention (EIBI); and (4) while there was limited availability of EIBI in general, intervention fidelity with regards to discrete trial teaching (DTT) was similar and increased with ongoing training. The professional and parental experiences were discussed in the context of policy, school involvement, and EIBI. This study illustrates the need to support children with autism and to
\end{abstract}


Running head: EIBI IN UK AND CHINA

consider cultural adaptations of evidence-based practice of behavior analysis for the affected population.

Keywords: Autism Spectrum Disorder; applied behavior analysis; Policy;

China; UK. 
Running head: EIBI IN UK AND CHINA

The prevalence of autism is estimated at least to be one in 160 children (WHO, (2019) and the development of these children and the lived experience of their families have become a global concern (Baxter et al., 2015; Global Research on Developmental Disabilities Collaborators, 2018). This is the case particularly in countries where autism prevalence is reported to be higher; for example, in the USA where it was estimated to be 1.85 per 100 in the USA (Shaw et al., 2020) and in the UK, where it was estimated to be 3.5 or even 4.2 per 100 in school-aged children (Dillenburger, Jordan, McKerr, \& Keenan, 2015). In China, reported autism prevalence is much lower, at 0.7-1.08 per 100 (Sun et al., 2019; Zhou et al., 2020). The stark difference in reported prevalence rates is much more likely to be a result of policy, resources, than of actual prevalence or incidence, and therefore, it is likely that autism prevalence rates rise as diagnostic systems improve. Clearly, the responses to increasing rates of autism are key concerns for policy-makers, communities, educators, and families.

There is ample evidence that applied behavior analysis (ABA)-based interventions can enhance these children's cognitive abilities, language skills, and social and emotional skills (Orinstein et al., 2014; Warren et al., 2011), and, consequently, ABA is considered the "gold standard" scientific basis of autism interventions and supports (Perry, Koudys, Prichard, \& Ho, 2019). However, cultural and regional differences influence decision-making processes during autism diagnosis and treatment (Mandell \& Novak, 2005) and the diagnosis of autism and the service delivery of ABA-based intervention programs differ significantly between developed and developing countries (Liao, Dillenburger, \& Buchanan, 2018; Wang, Wang, Guo, van Wijngaarden, \& Begeer, 2018). For example, in child-rearing more generally, the self-oriented individualism of Western culture expects children to become independent, have self-esteem, and become autonomous (Carteret, 2017), while Chinese cultural norms of collectivism focus much more on group-orientation, inter-generational contracts, and general obedience and compliance in children (Clayton, 2011; Tseng \& Wu, 2013). Clearly, these general cultural differences impact on autism-related public and educational policy and law and, particularly affect the introduction and adaptation of evidence-based approaches that were initially developed in the West. 
Running head: EIBI IN UK AND CHINA

\section{Autism policy in the UK and China}

There are several differences between the UK and China in terms of diagnosing autism, developing and introducing effective interventions, autism awareness, and public policies (Figure 1; see Appendix 1 for the reference list). One of the key differences was the near 40year delay in the first report of autism, with Kanner's (1943) work being recognized in the UK in the early 1940s, while autism was not reported in China until 1982 by Tao (1987). In the West, in 1980, the official diagnosis and classification of autism were defined in the third edition of the Diagnostic and Statistical Manual of Mental Disorders (DSM-3; American Psychiatric Association, 1980), yet it was only in 1995 when autism was included in the second edition of the Chinese Classification of Mental Disorders (CCMD-2) (Psychosis Branch of Chinese Medical Association \& Brain Hospital of Nanjing Medical University, 1995). In the

UK, recognition and adoption of policies and interventions to help children with autism grew since the 1960s (Wolff, 2004), while in China these developments did not start to gain momentum until the 1990s when parental concerns increased as they felt unable to help their children and were faced with the non-existence of effective treatment approaches (McCabe \& Tian, 2001; Wang, 2011).

The different levels of autism awareness were manifest in public policy and legislation. In the UK, diagnosis and support for people with disabilities has been available from the National Health Service (NHS) since 1948, at least at some degree (Hunter, 2018). With regards to autism policy, following a series of reviews from 2002 onwards and some regional initiatives the first UK autism strategy emerged in 2008, when the Welsh Assembly Government published its initial action plan (Welsh Government, 2009). The following year, an Autism Strategic Action Plan was published in Northern Ireland (Department of Health Social Services and Public Safety, 2009) and an updated version of the Welsh Strategic Action Plan was produced Welsh Government (2009). Around the same time, in England, the Autism Act (National Archives, 2009) and Fulfilling and Rewarding Lives: The Strategy for Adults with Autism in England (Department of Health and Social Care, 2010) aimed to promote autism awareness and improve the lives of people with autism. This meant that Special Educational Needs (SEN) were addressed in mainstream schools, and children with autism were to receive additional supports (Baron-Cohen et al., 2009). In Northern Ireland, 
Running head: EIBI IN UK AND CHINA

the Autism Act (Northern Ireland) (National Archives, 2011) required the specific development and publication of a cross-departmental autism strategy, addressing the health, social care and educational needs of children and adults with ASD. The Scottish Strategy for Autism was published in the same year (Scottish Government, 2011) and set out plans for service developments over a 10-year timespan. These initiatives have subsequently given rise to a number of specific changes in autism services for children, young people, and adults in the corresponding regions of the UK.

When the Children and Families Act took effect in 2014 (National Archives, 2014), the Statement of SEN and Learning Difficulties Assessment (LDA) was replaced by the Education, Health and Care Plan (EHCP) that covered educational, health, and social needs for people with a disability up until 25 years of age (Department of Education, 2015). In the UK, the National Institute for Health and Care Excellence (2013) set out processes for the identification and diagnosis of autism as well as guidance regarding challenging behavior recommending behavioral interventions and the inclusion of behavior analysts in multidisciplinary care team (National Institute for Health Care Excellence, 2015).

In China, policies regarding children with disabilities were derived from the 1987 Reform and Opening-Up policy (Deng, Poon-Mcbrayer, \& Farnsworth, 2001; McCabe, 2003), such as the 2006 Amended Compulsory Education Law and the Law on the Protection of Disabled Persons that promoted inclusive education for children with disabilities (An, Hu, \& Horn, 2018; Deng, Huang, Yan, \& Guan, 2014). It was not until 2006 that autism was first included under the mental disorder contexts in the second national sample survey of disabled persons (National Bureau of Statistics of China, 2007), and policies and laws for children with autism were considered under the context of people with mental disabilities (General Office of the State Council, 2016). Following the report Viewpoints on Promoting the Career Development of the Disabled (Central People's Government of the People's Republic of China, 2008), more family support policies (General Office of the State, 2009) and early intervention services (General Office of the State, 2010) were developed for children with autism, particularly those who live in poverty (Central People's Government of the People's Republic of China, 2011). 
Running head: EIBI IN UK AND CHINA

The Chinese Ministry of Health (2010) issued Guidelines for the Treatment and Rehabilitation of children with autism, in which ABA-based interventions were officially recommended. Families of young children (<6-years old), especially those with severe autism, that live in poverty, diagnosed with autism by an authorized hospital or issued with a Disability Certificate, can apply for funding from the local authority to receive services or training at a designated autism organization (China Disabled Persons Federation, 2008). Because of the Hukou restriction, i.e., a registration of Chinese permanent residence, residents from the developed urban cities most probably had better quality educational resources than those from rural regions (Wang et al., 2019).

Research regarding effective support for children and families affected by autism developed differently in each of these countries. In the UK, research covered a wide range of issues, including school-based ABA interventions (Eldevik, Eikeseth, Jahr, \& Smith, 2006; Foran et al., 2015; Grindle et al., 2012; Pitts, Gent, \& Hoerger, 2019). Chinese researchers began studying ABA by reviewing developed countries' laboratory results and practices (Wang \& Kang, 2011). Empirical studies into ABA increased in around 2005 (Liao, Dillenburger, He, Xu, \& Cai, 2020). However, few studies explored parents and professionals' experiences of autism and different intervention approaches across cultures with the exception of Ballantyne, Gillespie-Smith, and Wilson (2019) who conducted a survey to compare the public primary and secondary schoolteachers' knowledge and experience of working with individuals with autism in the United Kingdom $(n=51)$ and China $(n=59)$. Their results indicated the necessity of offering more autism-related training for teachers in both countries and that there were cultural differences between UK and Chinese teachers' understanding of autism.

\section{The practice of behavior analytic interventions}

Discrete Trial Training (DTT) is an ABA-based protocol that is used frequently and effectively as part of early intensive behavior intervention (EIBI), primarily to address a lack of basic imitation, social, or academic skills (Ferster \& Demyer, 1961, 1962; Lovaas, 1987, 2003; Lovaas, Koegel, Simmons, \& Long, 1973; McEachin, Smith, \& Lovaas, 1993; Smith, Eikeseth, Klevstrand, \& Lovaas, 1997). DTT is based on the A-B-C (Antecedent, Behavior, and 
Running head: EIBI IN UK AND CHINA

Consequence) contingency (Lerman, Valentino, \& LeBlanc, 2016) and skills are broken down into small, teachable moments, using the following steps: (1) an antecedent stimulus (A) is presented to set, cue, or trigger the target behavior, which involves creating the right environment to minimize any barriers to the correct response; (2) the target response, i.e., the target behavior (B) is performed by the child. Often, in early DTT, this requires careful shaping, i.e., the targeted response has to be broken down into small steps, from partially correct responses to entirely correct, unprompted responses. Especially during early DTT, physical, verbal, gestural, or pictorial prompt (P) may be necessary, if the behavior does not occur unprompted. The prompts then are phased out as soon as the target response is elicited without prompting; $(3)$ the Consequence $(C)$ is provided contingent on the correct response. The contingent use of positively reinforcing stimuli increases the likelihood of the target behavior recurring. Often, a reinforcer is a preferred item, i.e., certain food, social activities, or tangible items. Reinforcer or preference assessments are conducted before the start of DTT and repeated frequently ensure that reinforcers are used that function at any given time (Cooper, Heron, \& Heward, 2020). Greer (1997) coined the term "learn units" for these basic building blocks of pedagogy and suggested that the learning units can be used as a measure of the interaction between the teacher and the student (Smith, 2001).

Data collection based on direct behavior observations is a fundamental part of ABAbased interventions (Baer, Wolf, \& Risley, 1968; Cooper et al., 2020; Johnston \& Pennypacker, 2009). Details of data collection procedures differ between studies (Arnal et al., 2007; Babel, Martin, Fazzio, Arnal, \& Thomson, 2008; Jeanson et al., 2010). However, continuous data recording is preferred (Taubman, Leaf, McEachin, Papovich, \& Leaf, 2013) and should be based on evaluation criteria for the quality of service delivery (Langh, Cauvet, Hammar, \& Bolte, 2017). For example, Zhu, Hua, and Yuan (2020) remotely examined the procedural integrity of DTT and incidental teaching (IT; Hart \& Risley, 1975) of three Chinese teachers, and developed integrity criteria for their performance. Similarly, Babel et al. (2008) assessed the instructor's performance via the Discrete-Trials Teaching Evaluation Form (DTTEF). The DTTEF evaluates 21 components that make up quality DTT performance, including organizing teaching tasks before the start, managing antecedents, and dealing with correct or incorrect responses, prompt fading, and managing consequences. Higbee et 
Running head: EIBI IN UK AND CHINA

al. (2016) taught Brazilian undergraduate students how to conduct DTT, and indicated the importance of cross-cultural implementation of this strategy, considering the shortage of experienced supervisors and therapists in developing countries.

Apart from intervention integrity of DTT, more is known about EIBI generally (Green, Brennan, \& Fein, 2002; Klintwall \& Eikeseth, 2014; Remington et al., 2007; Smith, Hayward, Gale, Eikeseth, \& Klintwall, 2019). By-and-large, findings showed that ElBIs are successful, even when parent-managed (Mudford, Martin, Eikeseth, \& Bibby, 2001), although there are differences in relation to the intensity of intervention and supervision (Eldevik et al., 2006; Eldevik, Hastings, Jahr, \& Hughes, 2011; Peters-Scheffer, Didden, Mulders, \& Korzilius, 2010).

Most research regarding EIBI was conducted in developed countries in the West while little is known about it in the East. Few researchers have focused on the experience and intervention fidelity of parents and professionals using ABA-based interventions. In a small scale qualitative study, Liao et al. (2018) reported parental experiences of behavior analytic interventions in England and the Chinese mainland, and Liao et al. (2020) conducted a systematic review of behavior analytic interventions in China. The present paper extends the focus and offers an emic (inside) and an etic (outside) perspective (Morris, Leung, Ames, \& Lickel, 1999; Pike, 1954) to wider the contexts of society, educational and public policy, and integrates personal experiences with actual practice fidelity of behavior analytic services for children with autism in a Western developed country (United Kingdom), and an Eastern developing country (China).

\section{Research questions}

The research questions addressed in this paper are twofold:

1. What are the experiences of professionals and parents with regards to autism policy and school involvement in the UK and China;

2. What are the similarities and differences regarding the application of $A B A-b a s e d$ interventions, specifically, discrete trial training (DTT), in the two cultural regions. 
Running head: EIBI IN UK AND CHINA

\section{Method}

Semi-structured interviews and direct behavioral observations were carried out to identify and understand the similarities and differences in the application of ABA-based interventions in terms of lived experiences (Stake, 1995; Yates, 2003) and intervention fidelity of parents and professionals in the UK and China. Semi-structured interviews (Denzin \& Lincoln, 2005; Edwards \& Holland, 2013; Silverman, 2016) allowed for an in-depth analysis of the views and experiences of parents and practitioners and identified issues that were important for them. Direct behavioral observations (Bryman, 2015; Corbetta, 2003; Creswell, 2002) offered opportunities to analyze intervention fidelity of one specific ABAbased procedure (i.e., DTT) in different cultural regions.

\section{Terminology}

In the UK, professionals who directly deliver ABA-based intervention are called therapists or tutors and those who write child's individualized educational programs (IEP) and provide supervision or training for therapists/tutors and parents are called supervisors or behavioral consultants (Griffith, Fletcher, \& Hastings, 2012). Professionals in China who work directly with the children are called therapists or teachers, and supervisors are experienced trainers or teachers. In this paper, the term 'professional' is used for either 'therapist', i.e., those directly works with the children (i.e., tutors and therapists) or 'supervisor', i.e., those who run the IEP and deliver training (i.e., behavior consultants and supervisors). The term 'parent' is used for the primary direct caregiver of the child.

\section{Ethical considerations}

The School of Social Sciences, Education, and Social Work Ethics Committee at Queens University Belfast (QUB) granted ethical approval for the study. QUB research governance, data protection, and data storage procedures were adhered to.

\section{Participants and recruitment}

Semi-structured interviews. A total of 36 parents and professionals participated in the 
Running head: EIBI IN UK AND CHINA

semi-structured interviews; including 18 participants from the UK and 18 from China (Table 1). Four UK parent interviewees (P1-P4) were recruited from the NIU charity (all names are anonymized), and the remaining three UK parents (P5- P7) were recruited online from other agencies. All of the Chinese parent interviewees (P8- P14) were recruited via various autism schools located in the capital city where six of them had relocated temporarily for therapy, but the families usually lived in different parts of China.

There were 22 professional interviewees, with an equal number from each country (Table 2). In the UK sample, three interviewees (T1-T3) were recruited from NIU charity, five interviewees (T4- T8) were self-employed, and three interviewees (T9-T11) were recruited via friends or colleagues. In the Chinese sample, five of the professionals were the school's or center's founders (T12- T16), three of whom also had a child on the autism spectrum; four interviewees (T17- T19) were supervisors, and the remaining three (T20- T22) were therapists.

Direct observations. A total of five parents and three professionals participated in direct observations (Table 3). The UK parents, Daisy and Mary, conducted daily DTT with their children at home, supervised for two hours/month by a Board Certified Behavior Analyst (BCBA; a graduate-level training qualification in the USA). Mary had also hired a behavior analyst to deliver an additional 4-hour of training per week with her son. The Chinese parents, Ling, Meimei, and Wangjun, received short-term parent training at an autism school where they were guided by experienced supervisors.

The professional participants in direct observations (Table 4), included one professional from the UK and two professionals from China. In the UK, Jane delivered home-based training under BCBA supervision. The Chinese therapists, Xiaohong and Liumei, provided clinic-based training and were supervised by experienced supervisors.

\section{Research instruments}

Semi-structured interviews. The interview schedule was based on Keenan et al. (2007) and pilot tested by Liao et al. (2018). Four main topics were addressed to establish participants' personal experiences and perceptions of policy, society, school, and the 
Running head: EIBI IN UK AND CHINA

applications of EIBI practices. For example, interviewees were asked about their views on special needs education, mainstream inclusion, and social policy about children with autism. The participants were also asked to add comments they wanted to bring up at the end of the interview (for a copy of the full interview schedule see Liao, 2017).

Direct observations. The Metrics for Assessing the Application of Trials (MAAT; Table 5) was developed to record and analyze treatment fidelity during DTT (See Appendix 2 of a sample data recording sheet).

- The $1^{\text {st }}$ column (Definition) represents the level of treatment fidelity, with 10 for $100 \%$ fidelity and 1 for $100 \%$ non-fidelity. In the analysis, 10-7 was considered to be correctly implemented DTT, while 6-1 was considered an incorrect DTT application.

- The $2^{\text {nd }}$ column (Manipulation) gives details of the trial, with A standing for the correct delivery of an antecedent, $B$ standing for the correct emission of the target behavior ( $P$ denotes a prompt), and $\mathrm{C}$ standing for the contingent delivery of a previously assessed consequence or reinforcer.

- The $3^{\text {rd }}$ column (Explanation) offers a brief description of the details during the trial.

- The $4^{\text {th }}$ column $(S y m b o l)$ denotes the recording of the delivery of the 3 components (A$\mathrm{B}-\mathrm{C})$ of each learning unit during the session on the observation sheet.

The accurate delivery of the Antecedent stimulus (A) was denoted with a horizontal line. The accurate response of the child (Behavior, B) was denoted with a diagonal line (from top left to bottom right), and the contingent delivery of the Consequent stimulus (C) was denoted with a diagonal line (from bottom left to top right). If prompts were necessary, these were denoted with a P+.

The teaching materials used during DTT were individually tailored and provided by each parent or professional. In addition to the quantitative data collected during direct observations, extensive informal field notes were recorded. Additional information, such as timetable of the daily curriculum or teaching materials, were obtained from file archives. 
Running head: EIBI IN UK AND CHINA

\section{Research procedures}

Recruitment. The participants were recruited either online through social media or a direct call within autism organization. In the UK, the NIU charity was the main sample site; in China, AC School (all names anonymised) was the main sample site. Both institutions were founded in the early 1990s by parents of children with autism.

Semi-structured interviews. Interviews were conducted either via virtual video calls (e.g., Skype) or via face-to-face in a quiet room in the school. Interviews lasted for approx. 40-60 minutes. Full interview schedules are available elsewhere (Liao, 2017). All interviews were audio-recorded. Interviews in the UK, for five out of the seven parents and eight out of the 11 professionals, were conducted via Skype. The remainder of the UK interviews were conducted face-to-face. Interviews in China, for two out of the 11 professionals (Zheng \& Kate), were conducted virtually by QQ (a messaging application similar to Skype), the other Chinese professionals were interviewed face-to-face.

Direct observations. Direct observation sessions of DTT lasted on average 20 minutes (randomly selected from the total intervention time). The therapist and child were seated at a table to conduct the trials as usual, and the researcher sat in the background to observe and collect data. The researcher did not participate in the delivery of any trials. The number of trials for each session differed depending on the child's progress. The number of observation sessions differed between dyads and the interval between each observation session was one or two weeks.

In the UK sample, direct observations of DTTs occurred in participants' homes. Mary (mother) and her son Mark were observed for five sessions; Daisy (the mother) and her son David were observed for four sessions; Jane (the therapist) and Lily were observed for three sessions.

In the Chinese sample, direct observations took place at AC School or the children's homes. The practice of DTT between Ling (the mother) and Yun was observed for four 
Running head: EIBI IN UK AND CHINA

sessions; Meimei (the mother) and Cheng were observed on three occasions; Liumei (therapist) and Hua were observed at GC School. The DTT sessions of Wangjun (father) and Xiaobao were video-recorded as requested by the father. Not all of Wangjun's work was completed within the 20-minute timeframe, and a further 10-minute long video was randomly selected for analysis. The practice of DTT between Xiaohong (the therapist) and her students (Yun and Cheng) was observed at AC School. The first observation, with Yun lasted 15 minutes and the second observation with Cheng lasted 20 minutes.

\section{Data analysis}

Interviews: Thematic analysis (Braun \& Clarke, 2006; Miles, Huberman, \& Saldana, 2014) was used to organize and analyze the interview data, according to Braun and Clarke's (2006) four-step format. This included (1) Immersion in the data: Interview records were transcribed from the audio recordings. The transcripts were read and re-read a number of times to enable the researcher to immerse themselves in the data. (2) Initiating themes: Five themes emerged that were used to categorize the texts. These were policy, school, autism stigma, the extent of the applications of EIBI and the practices of DTT; (3) Developing and reviewing themes: Non-concrete or unambiguous codes (Ryan \& Bernard, 2003) were identified, e.g., different codes were developed for the UK and China under the "policy" theme. (4) Writing-up the report: After coding and categorizing the themes, the most pertinent direct quotations were extracted from the transcripts for the final write-up.

Direct observations. Using the MAAT matrix for the direct observations offered details for visual analysis as well as a quantitative score for intervention fidelity (Figure 3-10). The yaxis in the graphs shows the level of fidelity, and the horizontal dashed line shows the boundary between the high fidelity, i.e., an accurate application of trials (a score of 7 or above), and the low fidelity, i.e., an inaccurate application (a score of 6 or below). 


\section{Results}

\section{Semi-structured interviews}

Four subthemes emerged from the qualitative data: policy, education, autism stigma and the extent of the application of EIBI.

Policy context. Lack of public policy and support for autism emerged as a major theme in the policy context, especially for professionals in the leadership positions $(\mathrm{T} 1, \mathrm{~T} 2, \mathrm{~T} 12-16)$ who reported that autism organizations and charities had to finance themselves. All of the parents also reported that children lacked financial support for public services. Non-government funding resources were mentioned by several UK parents (P1, P2, P4, P7). Some of the parents stated they had received funding support from a charity and that this had helped to relieve some financial pressure.

Participants of both countries highlighted the fact that policy-makers often lacked sufficient understanding of individuals with autism and therefore did not provide adequate support for ABA-related services. For example, while some providers covered speech therapy for children who received a formal diagnosis, ABA-based services were not funded (P1, P2, P3, P4, P5, and P7). Some of the UK participants (T1 \& T6) experienced that local authorities funded therapies that look "nice", but some of them were not evidence-based.

They provided speech therapy, OT, educational psychologists, they addressed something. It's like putting drops into an empty glass; you won't get a full glass of water. That's how much they help. It's not a holistic approach. (UK therapist, Karen, T6)

Chinese participants also indicated the lack of national-level support for autism.

If one of the family members is diagnosed with a disability, parents have to pay for most of it. For example, they have to take the child for clinical diagnosis first. After that, they have to buy the services themselves. When they grow older, they have to think about who will take care of their child with a disability. They even have to think 
Running head: EIBI IN UK AND CHINA

about who will look after their child when they pass away. (Chinese founder \& mother of a child with autism, Chun, T12)

The lack of a nationally-recognized profession for working with individuals with autism was identified as a problem by many interviewees. Four out of the UK eleven professionals said that ABA was not recommended by the health services system or the government. Three of the UK professionals, Anna (T9), John (T10), and Adam (T11) believed this related to the historical development of ABA in dealing with individuals with autism.

Sometimes it's easier for me to go to a school and say I'm a speech and language therapist than a behavior analyst. Because it's an older profession and new professions are not as accepted so easily. So, what we have to do is try and be part of the establishment. Sometimes it's not good to change things too fast. (UK BCBA and Speech and Language therapist, Anna, T9)

AC School was one of the first non-governmental autism organizations to undertake parent-focused ABA training in the 1990s in China. The founder of AC School, Chun (T12) highlighted the challenges of adopting national-level professional qualifications like BCBA in China.

We have to think about Chinese culture, Chinese social structure, and the country's stage of [economic] development. That's how we build our service model... [We cannot build BCBA qualification like the US]. There is no legally recognized professional qualification for undertaking ABA-based interventions from the Ministry of Education or the Department of Human Resources and Social Security. (Chinese founder and mother of a child with autism, Chun, T12)

I studied SEN at university, but your teaching certificate is still the general education. There are no such SEN therapists' [certificates] in China. (Chinese therapist, Chow, T21)

It became clear that there was more support available for young children than for adolescents or adults on the autism spectrum. Participants from the UK (P1, P6, P7; T1-T9) and China (T12, T13, T17-T22) reported that young children with severe autism had a 
Running head: EIBI IN UK AND CHINA

greater chance of getting funding support from the government. Some participants

highlighted that low-income families received more support (P4, T9, T10, T12, T18, T20-22).

They tend to agree with only the more severe kids because the alternative is to pay even more if kids go for the residential school. (UK mother Caro, P7I)

Chinese participants (P8, P10, P11, P14; T12, T13, T17, T18) mentioned that normally children under 6-years old received more funding support from the local authority for training or services at local designated autism hospitals or organizations as long as the child had received a formal diagnosis from a qualified hospital and/or a Disability Certificate from the State's Disabled Federation.

Services were distributed unevenly so much so that different regions of the UK and China had different levels of services. For example, in the UK, participants indicated that England and Wales had better public service for autism than Northern Ireland.

It depends on which Trust you lived in, [and] what access to services you could get (UK BCBA, Laura, T2).

While there were some ABA schools in England funded by the government, parents stated that they would have to move house to be closer to the school in order to access it. Two $(P 6, P 7)$ out of the seven parents, from England, received government funding only because they succeeded in taking their local authority to the tribunal.

I basically got a lawyer on my side for one of the first times I spoke to the local authority, so they could see that I was not going to be messed around with... I had to have evidence that $A B A$ works, and that evidence I had to build up by first paying privately for ABA. They [parents] have to be rich to start with, but then have to pay for ABA and build up [an] evidence-base; you can persuade the State to take over the funding. (UK mother, Carol, P7)

It's a big struggle and big fight for the parents to keep this [tribunal] going. (UK therapist and mother or a child with autism, Stephanie, T8) 
Running head: EIBI IN UK AND CHINA

Parents had to provide proof that $A B A$ is evidence-based before the local authority would allow access. Jessica's (P6) son received 25 hours' funding a week to hire a therapist. This support also allowed them to pay for consultancy hours, which cost around $£ 1,400$ $(\approx \$ 1,800$, as of September 2020; this exchange rate used hereafter) per month. Carol (P7) started a campaign to help people from low socioeconomic backgrounds access ABA. Anna (T9), a freelancer employed by several schools in Wales, reported that ABA was firmly established in the state schools in North Wales. This was in stark contrast to the situation in other parts of the UK.

We are the only place in the British Isles where we have ABA firmly established in the state schools and education authorities welcoming it and working well with universities... What's interesting about our schools here is that they are fully under the umbrella of the government. They are very welcoming to ABA. There is a very strong emphasis on the school and the university, on working in the medium of Welsh. (UK BCBA and Speech and Language therapist, Anna, T9)

Similarly, in China, different regions were reported to have different support systems. Six of the seven Chinese parents were not from the major town, and they paid for the therapy out of their own pockets. Chun (T12) reported that residents could apply for a reimbursement of $¥ 6,000(\approx \$ 880)$ from the local authority if the child attended a government-designated autism organization. Chinese mother Bing (P11), who lived in a Southern province, indicated that parents from the local place of residence could receive $¥ 1000$ ( $\$ 150)$ a month from the local authority. Chang (P10) was a registered permanent resident of another Southern province, and her son received free services although she was not reimbursed for her son undertaking training programs in another province in Southern China. However, parents were not willing to send their children to local designated autism organizations.

If your child goes to the local designated organization, you can apply for reimbursement. The advantage is that it's free, but it isn't easy to guarantee teaching quality. (Chinese supervisor, Meiyin, T17) 
Running head: EIBI IN UK AND CHINA

We know about the services at the local designated autism organization, but the quality is too bad. It allows your child to access free training for three months. You know that the most important thing is the therapist. If he is not happy there, even at the risk of learning problematic behavior, we would rather let him stay home. (Chinese mother, Bing, P11)

Educational contexts. In both contexts, the UK and China, children with autism went to mainstream or Special Educational Needs (SEN) schools, depending on their abilities and skills. SEN schools (in China, these are called Intellectual Disability schools) had a higher staff to child ratio than mainstream schools and therapists had more training in teaching individuals with disabilities. Most SEN schools served students with different disabilities, such as physical disabilities, Down's syndrome, and autism spectrum disorders.

Mainstream schools in the UK faced challenges in incorporating ABA-based teaching methods. Many children with autism enrolled in mainstream schools that were allocated with a classroom or teaching assistant to facilitate their additional needs. The assistant usually worked with one specific child throughout the day, or they supported a number of children within the whole school. Some mainstream schools had a special unit or department for children with disabilities, including children with autism, as was the case with Linda's son (P5). The SEN units commonly had smaller class sizes and higher staff ratios. Children attending these units might be integrated into mainstream classes during certain lessons, such as $\mathrm{PE}$, and during recess and lunchtime.

Four of the seven parents of school-aged children (P1, P2, P5, and P6) and seven of the 11 professionals (T1, T2, T4, and $\mathrm{T} 5-\mathrm{T} 8$, ) reported that behavior analysts were not available or welcome at schools.

We provide the $A B A$ on our own, and [it is] not yet transferred into the school. And the school system doesn't follow the ABA principle. (UK mother, Linda, P5)

I was trying to get those [ABA professionals] into the school, but there was a big wall in the way. (UK mother, Mary, P2) 
Running head: EIBI IN UK AND CHINA

Both parents and professionals suggested children would benefit if more schools cooperated with behavior analysts, promoting skills such as imitating, interacting with a peer group, and generalized learning skills in a natural environment. Parents found that if school teachers understood the function of children's behavior by employing ABA-based strategies and principles, it would be easier for the teacher to teach the child with autism and also to control and manage the whole class. Mary (P2) illustrated the lack of the teacher's understanding of the function of her son's demand to escape/avoidance behavior, which led to missed learning opportunities.

Say, he was playing outside and then was taken inside when break time was over, and they were doing some work. My child would say "I'm tired"... [from the functional assessment, we know that] him saying 'I am tired' has the function of escaping a task demand. It's such a missed opportunity because the [school assistants] could work on his social skills. (UK mother, Mary, P2)

Chinese parents indicated that their children with autism risked being excluded from mainstream schools in some Chinese regions. For example, Chang (P10) reported that her son was suggested to leave his mainstream school. Therefore, all Chinese parents of the present study indicated they did not or intended not to, tell the school about their child's autism diagnosis.

If the school knows this situation [that the child has autism], we do not know whether they will take him or not. I feel the school will exclude these children. (Chinese mother, Xiang, P9)

Children like ours, not from the local place of residence, had a higher possibility of being excluded. Children need to have a school entrance interview. Some mainstream schools won't take my child. They are concerned my child may lower the level of the whole class in exams. (Chinese mother, Chang, P10)

Autism stigma. More of the Chinese participants rather than the UK participants reported stigmas attached to disabilities, including autism. Challenges of inclusive education resulted from the pressure from individuals' awareness and understanding of autism. 
Running head: EIBI IN UK AND CHINA

Parents will see the difference as a problem. My child is different from others. They think children flapping their hands is an embarrassing thing in public as typical children won't do that. In China, we say "mianzi," i.e., a child's different behavior makes parents lose face. It is a problem, so they want to change it [flapping their hands]. (Chinese supervisor, Lihua, T18)

The tag of "lifelong disability" may influence his future marriage prospects. (Chinese mother, Wuling, P13)

Not everybody in society is accepting of people with disabilities. Of course, even in the US, not everybody is accepting, but there are more discrimination and prejudices in Chinese society... There are a lot of people in China who are very accepting and very helpful [now], but parents are sometimes afraid to tell them; but once they tell them, they [may] find out their colleagues are very nice. (American supervisor, Kate, T19)

None of the parents applied for the Disabled Certificate, a legal certification to safeguard the rights and interests of disabled people (China Disabled Persons Federation, 2008). Autism has been categorized as a "mental disability", and parents mentioned that this term on the disabled certificate involved shame and stigma.

I don't want my child to be labeled [as having a disability]... It seems they [the local authority] provide $¥ 10,000$ ( $\approx 1,500$ ) of funding per year with this certificate. [It is] not very much [support]... And I do not think it is going to solve our problem. (Chinese mother, Xiang, P9)

People did not understand what autism is, but people did know what a mental disorder looked like, so everybody was scared. The word 'mental' just made people feel uncomfortable. I did not apply for the Disability Certificate [for my daughter] because I had the same feeling as the other parents... [Some parents held the opinion that] domestic shame should not be made public... Children with autism need money and professionals who can work with them, and they need societal support. (Chinese founder \& mother of a child with autism, Jing, T13) 
Running head: EIBI IN UK AND CHINA

However, some participants (P11, P13) indicated that in some regions of China children do not need a disability certificate. For example, Wuling (P13) from a Northern province indicated that their local authority only required confirmation of the autism diagnosis.

Early intensive behavior intervention (EIBI). Three out of the seven UK parents $(42.9 \%)$ and one out of the seven Chinese parents (14.3\%) had heard of EIBI. Six out of the eight UK professionals (75\%, three did not answer), and five out of the eight Chinese professionals (62.5\%, three did not answer) had heard about EIBI.

None of the parents reported that their child had received an EIBI program, and none of the Chinese professional interviewees reported they worked on an EIBI program. Three out of the eight UK professionals said they undertook EIBI programs with some families; these interviewees preferred to call it an ABA-based intervention because of low intensity of service delivery did not merit the label EIBI. Both the UK and Chinese professional interviewees highlighted the difficulty in achieving the recommended 20-40 hours per week in the EIBI model.

The participants said that the primary reasons for the low application of EIBI programs were funding constraints. The high staff cost restricted both the intensity (the number of hours required per week) and the duration of the program. Parents generally lacked external funding to support their children through ABA-based programs. On one hand, UK professionals Jennifer (T1) and Betty (T5) talked about government staff and General Practitioners (GP) in the health service lacking understanding of EIBI, while on the other hand, according to Carol (P7) the local government did not support intensive programs. In addition, a well-run EIBI program requires intensive individualized training and regular supervision.

They may have it in America that is not to say that things don't change, but at the minute, we can't offer [the required intensity]. (UK BCBA, Jennifer, T1)

For example, one of the UK mothers, Linda (P5) traveled approx. 40 miles to access ABA supervision for her child. Parents in China also faced difficulty in receiving ABA-based 
Running head: EIBI IN UK AND CHINA

programs. Six out of the seven Chinese parents moved house temporarily to access a quality service.

\section{Direct observations}

Table 6 shows the frequency and mean scores for all the direct observations of DTT trials in the UK and China. Figures 2-9 show the MAAT scores for each of the trials for parents and professionals across the observation sessions.

Daisy (UK mother; Table 6 and Figure 2) showed an increase in treatment fidelity across the four observation sessions (from 95.24\% in Observation 1 to $98.90 \%$ in Observation 4). In addition, the speed of trial delivery, i.e., the number of trials completed in 20 minutes, also increased, although this did not necessarily reflect increased fluency, as the target behaviors varied during different observation sessions. While she conducted most trials accurately, nine trials were inaccurate with three instances when a prompt was used without a subsequent reinforcer (Score 2). In addition, there were three instances of non-delivery of the reinforcer despite the occurrence of the target behavior (Score 3), two instances when the potential reinforcer was presented without the $A$ or the $B$ (Score 1 ), and one instance when the $\mathrm{C}$ was delivered before $\mathrm{B}$ (Score 6).

Mary (UK mother; Table 6 and Figure 3) worked with her son due to the financial burden of hiring a therapist. She consistently reached $100 \%$ accuracy in delivering trials. She competently used token economy, prompting, response and stimulus generalization, and incidental teaching. For example, she presented two token boards to display reinforcers. A token was given after each target response. A star was earned for every 10 tokens. After obtaining 5 stars, Mark was allowed to take a 10-minute break and select a toy to play with from a "surprise bag," that had been specially prepared by Mary and contained Mark's favorite toys. Mary recorded each trial on a datasheet.

Ling (Chinese mother; Table 6 and Figure 4) showed improvements in treatment fidelity across observations (from $64.00 \%$ in Observation 1, to $86.49 \%$ in Observation 4). She carried out most trials accurately. The 36 inaccurate trials included: 24 when the reinforcer (C) was not delivered (Score=3); five trials when only the $C$ (i.e., the potential reinforcer) was 
Running head: EIBI IN UK AND CHINA

presented without the A or the B (Score=1); five instances of presenting the consequence before the behavior had occurred (score=6); and two instances of using a prompt without the reinforcer being delivered, i.e., A-P-B, without C (Score=2).

Early on, Ling was not clear about the sequence of a trial. For example, when her son Yun knelt on the chair rather than sitting on it, Ling gave him a toy to play with and asked him to sit properly. Yun did not follow the request, and when Ling took away the toy, he began to scream. He quietened down when the mother left the toy beside him.

Meimei (Chinese mother; Table 6 and Figure 5) reached 100\% accuracy in delivering trials from Observation 1 to Observation 3, although there were still instances when she presented A repeatedly without waiting for a response (B), e.g., she asked, "what is it [a spoon]" again, even after the child gave the right answer.

Meimei also conducted generalization probes, e.g., one picture showed a light bulb and Meimei asked, "Cheng, can you show Mummy where else you could find a light bulb in this room?" Cheng looked around and pointed to a light bulb on the ceiling. Meimei used a token economy, drawing a tick in a box on the sheet for completed tasks and offering time with a favorite toy or activity for ten ticks. Meimei's husband video-recorded the sessions to allow the therapist to give feedback the next day.

Wangjun's (Chinese father; Table 6 and Figure 6) initial treatment fidelity was $88.89 \%$ in Observation 1 and rose to 100\% in Observation 4. He delivered eight inaccurate trials; in three of these trials Wangjun used a prompt without the reinforcer being delivered (Score 2 ); in four of these trials he inaccurately applied C before B (Score 6), and in one trial, he did not deliver C, despite the occurrence of B (Score 3). His teaching strategies included a prompt hierarchy (from full to partial prompting), task analysis, and skill response generalization.

In the first observation session, Wangjun taught Xiaobao to discriminate between the drinking water card and brushing teeth card. At first, Wangjun placed four cards in front of Xiaobao and asked him to give him two of them, but Xiaobao did not follow the instruction. Wangjun took away two cards and asked the child to give the drinking water card first and 
Running head: EIBI IN UK AND CHINA

then give the brushing teeth card. After the visual cards discrimination section, Wangjun presented a real drinking water bottle and asked Xiaobao: "what is this and what is it used for?"

Wangjun did not collect data during the whole observation. Wangjun's wife took a video recording to allow the therapist to give feedback the next day.

Jane (UK therapist; Table 6 and Figure 7) maintained 100\% treatment fidelity across the three observation sessions. Her intervention strategies were based on the behavior plan that was designed by a BCBA. A supervision meeting was observed during one of the observation sessions. A BCBA supervisor, the therapist Jane, and Lily's mother, Lucy, reviewed and discussed the behavior intervention plan and made plans for the next stage. Jane recorded each trial and calculated the correct percentages during the sessions. In addition, Jane recorded the function of behavior by using the $A B C$ format (AntecedentBehavior-Consequence) when Lily engaged in problem behavior, such as escape or avoidance behavior.

Xiaohong (Chinese therapist; Table 6 and Figure 8) achieved 100\% accuracy in delivering trials across the two observation sessions, though the children were distracted by the other children playing noisily. The child in the first observation was Yun. The observation included 17 trials within a 15-minute session. All the 17 trials scored above the threshold of six for accuracy. The child in the second observation was Cheng. The observation included 61 trials within a 20-minute session. No data collection was observed during two sessions, considering these were DTT practice demonstrations for parents.

Liumei (Chinese therapist; Table 6 and Figure 9) was observed for only one session. She achieved $100 \%$ accuracy delivering 57 trials within the 20 -minute session. All of the trials scored above the threshold for accuracy. The trials focused on four tasks; in Task four, Liumei asked the child to pronounce the words' qianbi' (pencil), 'shuzi' (comb), and 'jiandao' (scissors). Hua required vocal prompts as the pronunciation of these words was difficult. In addition, Hua was not always listening to instructions as he was chewing on a snack. Liumei did not collect any data during the observations. 


\section{Discussion}

An investigation of experiences and skills of professionals and parents from the UK and China was carried out in relation to autism-relevant policies, school involvement, and Applied Behavior Analysis (ABA)-based interventions. A total of 36 semi-structured interviews were conducted, and a number of parents and professionals were observed while they conducted discrete trial training. From the interview data, four subthemes emerged that included public policy, education, autism stigma, and limited awareness of early intensive behavior intervention (EIBI). Direct observations showed good levels of intervention fidelity for professionals and improvement in parental skills. Results of this study illustrated the need to consider cultural adaptations of ABA-based interventions.

Findings reported here show that there was a lack of support for autism and ABArelated services in both countries, the UK and China. Half of the parents relocated their home to access better resources. This is in contrast with the USA, where the Individuals with Disabilities Education Act (IDEA) stipulates that public education and services must cater for children with autism and their families (Department of Education, 2010; Shepley \& GrishamBrown, 2018) and where ABA-based services were endorsed by the United States Surgeon General (1999) a long time ago. In fact, all US States and Washington DC have laws to mandate health insurances to cover the needs of these children and families (National Conference of State Legislaters, 2018), including ABA-based therapies.

In the UK, the 2009 Autism Act and Fulfilling and Rewarding Lives: the Strategy for Adults with Autism in England (Department of Health and Social Care, 2010) promoted public autism awareness to improve the lives of people with autism. However, parents reported that local authorities had little knowledge of evidence-based interventions, and therefore, many of the parents interviewed here hired private therapists/tutors. Furthermore, many of the UK interviewees reported that special units in mainstream schools and specialist SEN schools did not utilize ABA-based interventions in children's educational program. Some schools even expressed clear views against the use of ABA principles and did not allow behavior analysts to visit or consult, even when the home-based ABA programs were successful. 
Running head: EIBI IN UK AND CHINA

Generally, parents in the UK and China had to pay out of pocket for ABA-based services. These findings confirm other studies that reported similar results (Foran et al., 2015; Keenan \& Dillenburger, 2020). Many of the UK parents indicated that they had to fight the school districts for more hours of assistance for their child. In some cases, in order to get their child's ABA-based program funded by the local authorities, they had to take the local authority to a tribunal. Similar findings have been reported by Johnson and Hastings (2002). Unfortunately, this situation has not improved since then (Byrne \& Byrne, 2005).

Interestingly, although the healthcare and educational systems were more developed in the UK than in China, the evidence-based approach of ABA-based intervention was not as widely endorsed in the UK as it was in China. One of the potential reasons for this was time differential when autism was recognized and the subsequent stages of the adoption of interventions for children with autism. It is possible that the more recent recognition of the autism diagnosis in China coincided with increased knowledge about ABA worldwide and this therefore afforded an openness to adopt ABA-based interventions, while in the UK, the earlier recognition of autism led to more traditional approaches promoted at that time, and it was more difficult to change established systems (Dillenburger, 2011).

Another reason might be that some professionals in the UK were not up to date with their training in evidence-based practice in autism; for example, the speech and language pathologist (Anna, T9), had been working in an already established healthcare and educational systems and therefore may have adhered to traditional methods rather than the interventions based on the latest research findings (Health Careers, 2015). Despite no evidence of effectiveness, some interventions have a long history in the UK and have become so rooted in people's practices that they are unable to shift along with new evidence. Clearly, it takes time and motivation to accept ABA-based intervention, although in the USA, ABA-based interventions were used in the 1960s and behavior analysts were a recognized profession in the late 1990s (Behavior Analyst Certification Board, 2020; National Autism Center, 2009; Shepley \& Grisham-Brown, 2018). Since 2017, the Behavior Analyst Certification Board has been accredited by the National Council for Certifying Agencies, the national-level quality accreditation body (Institute for Credentialing Excellence, 2017). Despite China having a shorter history than the UK in establishing ABA-based interventions, 
Running head: EIBI IN UK AND CHINA

proponents of ABA-based interventions were officially and directly supported (Beijing

Disabled Persons Federation, 2011; Jilin Province Disabled Persons Federation, 2016; Ministry of Health, 2010).

In China, some provinces required parents to apply for a Disability Certificate in order to receive official support, and the present study found that parents were concerned about the social stigma attached to the Disability Certificate and therefore were reluctant to apply. Parents were worried about the implications of the terms "mental" or "psychiatric" on the disability tag of their children. Fortunately, a Disability Certificate was not a prerequisite for services in some provinces, although a formal diagnostic assessment from authoritative hospitals was required (Jiangsu Province Department of Public Information, 2013; Shanxi Province Disabled Federation, 2015; Tianjin city Disabled Federation, 2013).

One of the biggest challenges faced by the Chinese children with autism was inclusive education, even though the education policy for children with disabilities in China was called "Learning in a Regular Class" (Chen \& Lan, 2014; Fei, 2007; Huang \& Wheeler, 2007; Ministry of Education, 1993). This policy was developed by the State Department of Education to include children with disabilities in mainstream education and to remove enrolment tests for these children (Chen \& Lan, 2014; Fei, 2007; Huang \& Wheeler, 2007). Though the education system is becoming more inclusive than before, inclusive education regarding individual difference still remains to be established (Su et al., 2020). Chinese parents reported that headteachers were worried that children on the autism spectrum would perform poorly, resulting in the lowering of the whole class average score in exams and even affecting the academic performance of the other children in a class. Therefore, it is not surprising that most of the Chinese parents in the present study had not revealed their child's autism diagnosis to the school. This finding was consistent with several previous studies (An et al., 2018; Clark \& Zhou, 2005; Huang \& Wheeler, 2007; McCabe, 2007; Sun et al., 2013).

The other challenge that Chinese parents highlighted was that they had to relocate to access high-quality services. One of the main reasons parents moved house was the shortage of qualified professionals working with autism in their home province. Clearly, 
Running head: EIBI IN UK AND CHINA

there is a huge shortage of good quality services in undeveloped provinces, or small cities in China (Clark \& Zhou, 2005; Huang, Jia, \& Wheeler, 2013) and more behavior analysts were needed urgently. The profession of Chinese behavior analysts is suggested to be established as it has been in the USA. In addition, the Hukou system is restrictive because access to services was limited to the locally designated autism rehabilitation organizations. For example, one of the Chinese cities offered reasonably good support for children up to the age of 14-years of age only for children who lived in the city and only at locally designated rehabilitation organizations (Jiangsu Province Department of Public Information, 2013).

Both, UK and Chinese participants reported limited awareness of early intensive behavior intervention (EIBI) and very low application rates for EIBI. This finding was consistent with Mudford, Martin, Eikeseth, and Bibby (2001). The reasons for the low levels of EIBI in China and the UK were that parents found it impossible to afford the required level of high intensity and duration of the programs financially. In addition, professionals indicated that EIBI program required intensive individualized training and regular supervision and reported a significant shortage of resources in both in UK and China.

An interesting finding of the present study related to cultural differences. Clearly, the service model from Western developed countries could not simply be replicated in China, as Chun (T12) pointed out: "We have to think about Chinese culture, Chinese social structure, and the stage of [economic] development. That's how we build our service model". The policy, cultural, economic, social, and practical differences need be considered, including the introduction of lower intensity school-based ABA programs that have been shown to work for children with autism in the UK (Remington et al., 2007; Grindle et al., 2012; Foran et al., 2015) as well as in other parts of the world (Eldevik, Eikeseth, Jahr, \& Smith, 2006; PetersScheffer et al., 2010).

Finally, the results from the behavior observations of DTTs were similar in the two culturally-contrasting sample areas. The treatment fidelity of parents who worked as therapists with their children increased with training across trials. When trials were inaccurately carried out, this was mainly due to both UK and Chinese parents not delivering reinforcers contingent on the child's behavior. The treatment fidelity by professionals 
Running head: EIBI IN UK AND CHINA

working with children was high for both UK and Chinese therapists. However, the main difference of the practice of DTT is that Chinese participants lack sufficient data collection. Video recording is the tool that used frequently. The possible reason might be because of the limited awareness of and the shortage of data collection training.

In conclusion, one of the main contributions of the present study was that it enriched with empirical data the practice and application of ABA-based intervention programs in two contrasting cultural regions. In addition, treatment fidelity is notoriously difficult to assess. While there were some elaborate systems for assessment available, generally these lend themselves to clinic-based, professionally delivered DTT. The present study was communitybased and observations applied to different cultural and societal contexts, and therefore complex assessment arrangements were not suitable. Consequently, a simple observation system was developed (MAAT; Table 5). The MAAT offers a basic measure of intervention accuracy for individual trials in DTT. It allows for some flexibility in the measure, as trials that score between seven and ten are considered accurate. Trials in this category do not include real mistakes, but they were not always completed fully, i.e., contingent on $A$ being presented, B was elicited (prompted, where needed), and C was delivered contingent on B. Trials were considered inaccurate if $\mathrm{A}$ and/or $\mathrm{C}$ were delivered non-contingently. This relatively simple measure of fidelity of trials proved to be easy to apply and reliable as welltrained therapists scored $100 \%$, while scores for parents in training increased over time. To the authors' knowledge, this was the first study to explore the similarities and differences of parent and professional experiences of early behavior analytic interventions in the UK and China. In particular, this study offered rich empirical data on the application of DTT across these different settings.

Like all research, this study has several limitations. While the study showcased crossnational research in terms of both an emic and an etic perspective to illustrate parent and professional lived experiences in two contrasting political, cultural, and societal regions (i.e., the UK and China), it did not present a full cultural analysis, due to the limited sample size and relatively narrow focus. Thus, the subjective description of personal experiences might generate bias, although, having said this, when findings were compared with other larger studies (e.g., Keenan et al., 2007), the number of interviewees in this study seemed 
Running head: EIBI IN UK AND CHINA

sufficient to achieved data saturation (Neuman, 2013). When interview data are combined with direct behavior observation methodology, the synergetic results gave some indication of intervention fidelity and behavioral outcomes for the children during or after DTT. It is expected that further large-scale research in other cultural contexts may confirm the preliminary findings reported here.

In sum, the present study found differences in autism and ABA awareness, policy, and educational contexts in two disparate cultural contexts (UK and China). Despite these major differences, direct observations of applying ABA-based interventions, specifically, Discrete Trial Training (DTT), showed that intervention fidelity was similar across professionals and parents were able to learn to carry out DTTs with sufficient fidelity to have a positive impact on their children's lives. 


\section{Funding:}

The initial research reported here was conducted in part fulfilment of the requirement for the Ph.D. degree of the first author under the supervision of the second author, funded by a Queens University/Chinese Scholarship Committee. Further work was funded by the National Science Foundation of China (Grant No. 32000762) and the Natural Science Foundation of Guangdong Province, China (Grant No. 2018A030310094).

\section{Disclosure statement:}

No potential conflict of interest was reported by either of the authors.

\section{References:}

American Psychiatric Association. (1980). Diagnostic and statistical manual of mental disorders (3rd ed.). Washington, DC: Author.

An, Z. G., Hu, X., \& Horn, E. (2018). Chinese inclusive education: The past, present, and future. Intervention in School and Clinic, 54(2), 118-122. doi:10.1177/1053451218765244

Arnal, L., Fazzio, D., Martin, G., Yu, C., Keilback, L., \& Starke, M. (2007). Instructing University Students to Conduct Discrete-Trials Teaching with Confederates Simulating Children with Autism. Developmental Disabilities Bulletin, 35, 131-147.

Babel, D. A., Martin, G. L., Fazzio, D., Arnal, L., \& Thomson, K. (2008). Assessment of the reliability and validity of the discrete-trials teaching evaluation form. Developmental Disabilities Bulletin, 36(1-2), 67-80.

Baer, D. M., Wolf, M. M., \& Risley, T. R. (1968). Some current dimensions of applied behavior analysis. Journal of Applied Behavior Analysis, 1(1), 91-97. doi:10.1901/jaba.1968.1-91

Ballantyne, C., Gillespie-Smith, K., \& Wilson, C. (2019). A comparison of knowledge and experience of Autism Spectrum Disorder among teachers in the United Kingdom and China. International Journal of Disability, Development and Education.

Baron-Cohen, S., Scott, F. J., Allison, C., Williams, J., Bolton, P., Matthews, F. E., \& Brayne, C. (2009). Prevalence of autism-spectrum conditions: UK school-based population study. The British Journal of Psychiatry: The Journal of Mental Science, 194(6), 500-509. doi:10.1192/bjp.bp.108.059345 
Baxter, A. J., Brugha, T. S., Erskine, H. E., Scheurer, R. W., Vos, T., \& Scott, J. G. (2015). The epidemiology and global burden of autism spectrum disorders. Psychol Med, 45(3), 601-613.

Behavior Analyst Certification Board. (2020). About the BACB. Retrieved from https://bacb.com/about-the-bacb/

Beijing Disabled Persons Federation. (2011). Beijing Disabled Person's Federation hosted the 2011 continuing educaiton for core teachers [市残联举办 2011 年民办残疾人康复 机构骨干教师继续教育培训]. Retrieved from http://www.bdpf.org.cn/zxpd/gzdt/c6113/content.html

Braun, V., \& Clarke, V. (2006). Using thematic analysis in psychology. Qualitative Research in Psychology, 3(2), 77-101. doi:10.1191/1478088706qp063oa

Bryman, A. (2015). Social research methods (5 ed.). Oxford: Oxford university press.

Carteret, M. (2017). How individualism and collectivism manifest in child rearing practices. Dimensions of culture.

Central People's Government of the People's Republic of China. (2008). Viewpoints of the Central Committee of the Communist Party of China and State Council on promoting the development of undertakings for people with disabled. [中共中央、国务院关于 促进残疾人事业发展的意见]. Retrieved from https://www.chinacourt.org/article/detail/2008/04/id/299007.shtml

Central People's Government of the People's Republic of China. (2011). Colourful dream action plan of implementation scheme on helping children with disability. [残疾儿童 康复救助 “七彩梦行动计划” 实施方案]. Retrieved from http://www.gov.cn/fwxx/cjr/content_2440510.htmfiles/1708/content_2440510.html

Chen, Y., \& Lan, J. (2014). Analysis of current policies and regulations on learning in general classroom in China. The Disabled Study, 4, 61-64.

China Disabled Persons Federation. (2008). Guidance of the Certificate of Disability in the Second Time Period

Clark, E., \& Zhou, Z. (2005). Autism in China: From acupuncture to applied behavior analysis. Psychology in the Schools, 42(3), 285-295.

Clayton, C. L. (2011). Contemporary British chinese parenting: Beyond cultural values. Childhoods Today, 5(1), 1-25.

Cooper, J., Heron, T., \& Heward, W. (2007). Applied behavior analysis (2 ed.). Upper Saddle River, NJ: Pearson Prentice Hall.

Corbetta, P. (2003). Social research: Theory, methods and techniques (1 ed.). London: SAGE Publications. 
Running head: EIBI IN UK AND CHINA

Creswell, J. W. (2002). Research design: Qualitative, quantitative, and mixed methods approaches (2 ed.). California: SAGE Publications.

Deng, M., Huang, W., Yan, T., \& Guan, W. (2014). Current situation and discussions of education and rehabilitation of children with autism in China. [孤独症儿童教育康复 现状与思考]. Disability Research, 2, 37-42.

Deng, M., Poon-Mcbrayer, K. F., \& Farnsworth, E. B. (2001). The development of special education in China: A sociocultural review. Remedial and Special Education, 22(5), 288-298. doi:10.1177/074193250102200504

Denzin, N. K., \& Lincoln, Y. S. (2005). The SAGE handbook of qualitative research. London: SAGE Publications.

Department of Education. (2010). Thirty-five years of progress in educating children with disabilities through IDEA. Retrieved from

https://www2.ed.gov/about/offices/list/osers/idea35/history/index_pg12.html\#: :text= Thirty-

five $\% 20$ Years $\% 20$ of $\% 20$ Progress $\% 20$ in $\% 20$ Educating $\% 20$ Children $\% 20$ With, for $\% 20$ infants $\% 2$ C $\% 20$ toddlers $\% 2 \mathrm{C} \% 20$ children $\% 2 \mathrm{C} \% 20$ and $\% 20$ youths $\% 20$ with $\% 20$ disabi lities.

Department of Education. (2015). Children with special educational needs and disabilities (SEND) Retrieved from https://www.gov.uk/children-with-special-educationalneeds/extra-SEN-help

Department of Health and Social Care. (2010). Fulfilling and rewarding lives: The strategy for adults with autism in England. Retrieved from https://www.gov.uk/government/news/fulfilling-and-rewarding-lives-the-strategy-foradults-with-autism-in-england

Department of Health Social Services and Public Safety. (2009). Autistic spectrum disorder (ASD) strategic action plan 2008/09-2010/11. Belfast: Department of Health Social Services and Public Safety.

Dillenburger, K., Jordan, J. A., McKerr, L., \& Keenan, M. (2015). The Millennium child with autism: Early childhood trajectories for health, education and economic wellbeing. Developmental Neurorehabilitation, 18(1), 37-46. doi:10.3109/17518423.2014.964378

Edwards, R., \& Holland, J. (2013). What is qualitative interviewing? London: A\&C Black.

Eldevik, S., Eikeseth, S., Jahr, E., \& Smith, T. (2006). Effects of low-intensity behavioral treatment for children with autism and mental retardation. Journal of Autism and Developmental Disorders, 36(2), 211-224. doi:10.1007/s10803-005-0058-x

Eldevik, S., Hastings, R. P., Jahr, E., \& Hughes, J. C. (2011). Outcomes of behavioral intervention for children with autism in mainstream pre-school settings. Journal of Autism and Developmental Disorders, 42(2), 210-220. doi:10.1007/s10803-011-12349 
Ellsworth, N. J., \& Chun, Z. (2007). Progress and Challenges in China's Special Education Development: Observations, Reflections, and Recommendations. Remedial and Special Education, 28(1), 58-64. doi:10.1177/07419325070280010601

Fei, X. (2007). The Chinese "Learning in a Regular Classroom": History, current situation, and prospects. Chinese Education \& Society, 40(4), 8-20. doi:10.2753/CED10611932400401

Ferster, C. B., \& Demyer, M. K. (1961). The development of performances in autistic children in an automatically controlled environment. Journal of Chronic Diseases, 13(4), 312-345.

Ferster, C. B., \& Demyer, M. K. (1962). A method for the experimental analysis of the behavior of autistic children. The American Journal of Orthopsychiatry, 32(1), 89-98.

Foran, D., Hoerger, M., Philpott, H., Jones, E. W., Hughes, J. C., \& Morgan, J. (2015). Using applied behaviour analysis as standard practice in a UK special needs school. British Journal of Special Education, 42(1), 34-52. doi:10.1111/1467-8578.12088

General Office of the State, C. (2009). Notice from the General Office of the State Council to further accelerate the development of special needs education. [国务院办公厅转发教 育部等部门关于进一步加快特殊教育事业发展意见的通知].

General Office of the State, C. (2010). Notice of guidance from General Office of the State Council to China Disabled Person's Federation and other departments about accelerating social security and service system for people with disability. [国务院办 公厅转发中国残联等部门和单位关于加快推进残疾人社会保障体系和服务体系 建设指导意见的通知].

General Office of the State Council. (2016). National Action Plan for Disability Prevention. [国家残疾预防行动计划 $(2016-2020$ 年)]. Retrieved from http://www.cdpf.org.cn/ghjh/qtgh/201611/t20161101_572184.shtml

Global Research on Developmental Disabilities Collaborators. (2018). Developmental disabilities among children younger than 5 years in 195 countries and territories, 1990-2016: A systematic analysis for the Global Burden of Disease Study 2016. Lancet Global Health, 6(10), e1100-e1121. doi:https://doi.org/10.1016/S2214$\underline{109 X(18) 30309-7}$

Green, G., Brennan, L. C., \& Fein, D. (2002). Intensive behavioral treatment for a toddler at high risk for autism. Behavior Modification, 26(1), 69-102.

Greer, R. D. (1997). The comprehensive application of behavior analysis to schooling (CABAS $\left.{ }^{\circledR}\right)$. Behavior and Social Issues, 7(1), 59-63.

Griffith, G. M., Fletcher, R., \& Hastings, R. P. (2012). A national UK census of applied behavior analysis school provision for children with autism. Research in Autism Spectrum Disorders, 6(2), 798-805. doi:10.1016/j.rasd.2011.10.014 
Grindle, C. F., Hastings, R. P., Saville, M., Hughes, J. C., Huxley, K., Kovshoff, H., . . . Remington, B. (2012). Outcomes of a behavioral education model for children with autism in a mainstream school setting. Behavior Modification, 36(3), 298-319. doi:10.1177/0145445512441199

Hart, B., \& Risley, T. R. (1975). Incidental teaching of language in the preschool. Journal of Applied Behavior Analysis, 8(4), 411-420. doi:10.1901/jaba.1975.8-411

Health Careers. (2015). Speech and language therapist. Retrieved from https://www.healthcareers.nhs.uk/explore-roles/allied-health-professionals/speechand-language-therapist

Higbee, T. S., Aporta, A. P., Resende, A., Nogueira, M., Goyos, C., \& Pollard, J. S. (2016). Interactive computer training to teach discrete-trial instruction to undergraduates and special educators in Brazil: A replication and extension. Journal of Applied Behavior Analysis, 49(4), 780-793. doi:10.1002/jaba.329

Huang, A. X., \& Wheeler, J. J. (2007). Including children with autism in general education in China. Childhood Education, 83(6), 356-360.

Hunter, D. J. (2018). Looking forward to the next 70 years: from a National Ill-Health Service to a National Health System. Health Economics, Policy and Law, 14(1), 1114. doi:10.1017/S1744133118000099

Institute for Credentialing Excellence. (2017). National commission for certifying agencies (NCCA) standards. Retrieved from http://www.credentialingexcellence.org/p/cm/ld/fid=66.

Jeanson, B., Thiessen, C., Thomson, K., Vermeulen, R., Martin, G. L., \& Yu, C. T. (2010). Field testing of the discrete-trials teaching evaluation form. Research in Autism Spectrum Disorders, 4(4), 718-723. doi:https://doi.org/10.1016/j.rasd.2010.01.010

Jiangsu Province Department of Public Information. (2013). Notice from the local government office about transmitting rehabilitation reimbursement for children with disability. [市政府办公室关于转发苏州市残疾儿童康复补助办法的通知]. Retrieved from http://www.jiangsu.gov.cn/jsgov/sx/shengxs/suzhous/201306/t20130604383741.html

Jilin Province Disabled Persons Federation. (2016). Jilin Province Disabled Persons Federation held the 2016 parents' education. [吉林省残疾人康复中心 2016 年第七 期家长培训通知]. Retrieved from http://www.jldpf.org.cn/kangfuzhongxin/kfxxgg/201607/t20160720_2347620.html

Johnson, E., \& Hastings, R. P. (2002). Facilitating factors and barriers to the implementation of intensive home-based behavioural intervention for young children with autism. Child: Care, Health and Development, 28(2), 123-129. doi:10.1046/j.13652214.2002.00251.x

Johnston, J. M., \& Pennypacker, H. S. (2009). Strategies and tactics of behavioral research (3rd ed.). New York: Routledge/Taylor \& Francis Group. 
Running head: EIBI IN UK AND CHINA

Kanner, L. (1943). Autistic disturbances of affective contact. Nervous Child, 2, 217-250.

Keenan, M., \& Dillenburger, K. (2020). Drama in the courtroom: Defending the rights of children diagnosed with autism. The Barrister. Retrieved from http://www.barristermagazine.com/drama-in-the-courtroom-defending-the-rights-ofchildren-diagnosed-with-autism/

Klintwall, L., \& Eikeseth, S. (2014). Early and intensive behavioral intervention (EIBI) in autism Comprehensive Guide to Autism. New York: Springer Science and Business Media New York.

Langh, U., Cauvet, E., Hammar, M., \& Bolte, S. (2017). Cross-cultural validation of the York measure of quality of intensive behavioral intervention. Behavior Modification, 41(6), 808-828. doi:10.1177/0145445517719397

Lerman, D. C., Valentino, A. L., \& LeBlanc, L. A. (2016). Discrete trial training. In R. Lang, T. B. Hancock, \& N. N. Singh (Eds.), Early intervention for young children with autism spectrum disorder. New York: Springer.

Liao, Y. (2017). Early applied behavior analytic interventions for children diagnosed with autism spectrum disorder: A cross-national study of the UK and China. (Unpublished Ph.D. Thesis), Queen's University Belfast, Belfast.

Liao, Y., Dillenburger, K., \& Buchanan, I. (2018). Does culture matter in ABA-based autism interventions? Parent and professional experiences in the UK and China. European Journal of Behavior Analysis, 19(1), 11-29. doi:10.1080/15021149.2017.1399657

Liao, Y., Dillenburger, K., He, W., Xu, Y., \& Cai, H. (2020). A systematic review of applied behavior analytic interventions for children with autism in Mainland China. Review Journal of Autism and Developmental Disorders. doi:10.1007/s40489-020-00196-w

Lovaas, O. I. (1987). Behavioral treatment and normal educational and intellectual functioning in young autistic children. Journal of Consulting and Clinical Psychology, 55(1), 3-9. doi:http://dx.doi.org/10.1037/0022-006X.55.1.3

Lovaas, O. I. (2003). Teaching individuals with developmental delays: Basic intervention techniques. Austin, TX: PRO-ED.

Lovaas, O. I., Koegel, R., Simmons, Q. S., \& Long, J. S. (1973). Some generalization and follow-up measures on autistic children in behavior therapy. Journal of Applied Behaviour Analysis, 6(1), 131-165.

Mandell, D. S., \& Novak, M. (2005). The role of culture in families' treatment decisions for children with autism spectrum disorders. Mental Retardation and Developmental Disabilities Research Reviews, 11(2), 110-115. doi:10.1002/mrdd.20061

McCabe, H. (2003). The beginnings of inclusion in the People's Republic of China. Research and Practice for Persons with Severe Disabilities, 28(1), 16-22.

doi:10.2511/rpsd.28.1.16 
McCabe, H. (2007). Parent advocacy in the face of adversity autism and families in the People's Republic of China. Focus on Autism and Other Developmental Disabilities, 22(1), 39-50. doi:10.1177/10883576070220010501

McCabe, H. (2008). Two decades of serving children with autism in the People's Republic of China: Achievements and challenges of a state - run mental health center. Disability \& Society, 23(3), 271-282. doi:10.1080/09687590801954059

McCabe, H., \& Tian, H. (2001). Early intervention for children with autism in the people's republic of china: A focus on parent training. Journal of International Special Needs Education, 4, 39-43.

McEachin, J. J., Smith, T., \& Lovaas, O. I. (1993). Long-term outcome for children with autism who received early intensive behavioral treatment. American Journal of Mental Retardation, 97(4), 359-372; discussion 373-391.

Miles, M. B., Huberman, A. M., \& Saldana, J. (2014). Qualitative data analysis: A methods sourcebook. London: SAGE Publications.

Ministry of Education. (1993). Proposed Regulation for Implementing Learning in Regular Classroom for Children and Adolescents with disability. [关于开展残疾儿童少年随 班就读工作的试行办法]. Beijing: Arthor.

Ministry of Health. (2010). Guidelines for the treatment and rehabilitation of children with autism. [儿童孤独症诊疗康复指南]. Retrieved from http://www.gov.cn/zwgk/2010-08/16/content_1680727.htm

Morris, M. W., Leung, K., Ames, D., \& Lickel, B. (1999). Views from inside and outside: Intergrating emic and etic insights about culture and jusitce judegement. Academy of Management Review, 24(4), 781-796.

Mudford, O. C., Martin, N. T., Eikeseth, S., \& Bibby, P. (2001). Parent-managed behavioral treatment for preschool children with autism: Some characteristics of UK programs. Research in Developmental Disabilities, 22(3), 173-182. doi:10.1016/S08914222(01)00066-X

National Archives. (2009). Autism Act 2009. Retrieved from http://www.legislation.gov.uk/ukpga/2009/15/contentsfiles/1537/contents.html

National Archives. (2011). Autism Act (Northern Ireland) 2011. Retrieved from http://www.legislation.gov.uk/nia/2011/27/contents/enactedfiles/2977/enacted.html

National Archives. (2014). Children and Families Act 2014. Retrieved from http://www.legislation.gov.uk/ukpga/2014/6/contents/enacted

National Autism Center. (2009). Evidence-based practice and autism in the schools: A guide to providing appropriate interventions to students with autism spectrum disorders. Randolph, MA: Author. 
Running head: EIBI IN UK AND CHINA

National Bureau of Statistics of China. (2007). Main statistic report from Second National Sample Survey on Disability in 2006. [2006 年第二次全国残疾人抽样调查主要数 据公报]. Retrieved from http://www.cdpf.org.cn/sjzx/cjrgk/200711/t20071121_387540.shtml

National Conference of State Legislaters. (2018). Autism and insurance coverage: State laws. Retrieved from https://www.ncsl.org/research/health/autism-and-insurance-coverage$\underline{\text { state-laws.aspx }}$

National Institute for Health and Care Excellence. (2013). Autism spectrum disorder in under 19s: Support and management. Retrieved from https://www.nice.org.uk/Guidance/CG170

National Institute for Health Care Excellence. (2015). Challenging behaviour and learning disabilities: Prevention and interventions for people with learning disabilities whose behaviour challenges. Retrieved from https://www.nice.org.uk/guidance/ng11

Neuman, W. L. (2013). Social research methods: Quantitative and qualitative approaches (7 ed.). London: Pearson.

Orinstein, A. J., Helt, M., Troyb, E., Tyson, K. E., Barton, M. L., Eigsti, I., . . Fein, D. (2014). Intervention for optimal outcome in children and adolescents with a history of autism. Journal of Developmental and Behavioral Pediatrics, 35(4), 247-256. doi:10.1097/DBP.0000000000000037

Perry, A., Koudys, J., Prichard, A., \& Ho, H. (2019). Follow-up study of youth who received EIBI as young children. Behavior Modification, 43(2), 181-201. doi:10.1177/0145445517746916

Peters-Scheffer, N., Didden, R., Mulders, M., \& Korzilius, H. (2010). Low intensity behavioral treatment supplementing preschool services for young children with autism spectrum disorders and severe to mild intellectual disability. Research in Developmental Disabilities, 31(6), 1678-1684. doi:10.1016/j.ridd.2010.04.008

Pike, K. L. (1954). Language in relation to a unified theory of the structure of human behavior. Glendale, CA: Summer Institute of Linguistics.

Pitts, L., Gent, S., \& Hoerger, M. L. (2019). Reducing pupils' barriers to learning in a special needs school: integrating applied behaviour analysis into Key Stages 1-3. British Journal of Special Education, 46(1), 94-112. doi:https://doi.org/10.1111/1467$\underline{8578.12251}$

Remington, B., Hastings, R. P., Kovshoff, H., Espinosa, F. d., Jahr, E., Brown, T., . . Ward, N. (2007). Early intensive behavioral intervention: Outcomes for children with autism and their parents after two years. American Journal on Mental Retardation, 112(6), 418-438. doi:10.1352/0895-8017(2007)112[418:EIBIOF]2.0.CO;2

Ryan, G. W., \& Bernard, H. R. (2003). Techniques to identify themes. Field Methods, 15(1), 85-109. doi:10.1177/1525822X02239569 
Scottish Government. (2011). The scottish strategy for autism. Retrieved from https://www.gov.scot/publications/scottish-strategy-autism/

Shanxi Province Disabled Federation. (2015). Notice issued by Shanxi Province Disabled Federation about "Implementing rehabilitation training project for children with intellectual disability (0-6 years old)" and "Implementing rehabilitation training for children with autism (3-6 years old)". [关于印发《山西省 0-6 岁智力残疾儿童康 复训练救助项目实施办法》和《山西省 3-6 岁孤独症儿童康复训练救助项目实 施办法》的通知]. Retrieved from http://www.sxdpf.org.cn/info/info_info.aspx?info_id=8424

Shaw, K. A., Maenner, M. J., Baio, J., Washington, A., Christensen, D. L., Wiggins, L. D., . . Dietz, P. M. (2020). Early identification of autism spectrum disorder among children aged 4 years - Early autism and developmental disabilities monitoring network, six sites, United States, 2016. MMWR Surveill Summ 2020, 69(3), 1-11. doi:http://dx.doi.org/10.15585/mmwr.ss6903alexternal

Shepley, C., \& Grisham-Brown, J. (2018). Applied Behavior Analysis in Early Childhood Education: An Overview of Policies, Research, Blended Practices, and the Curriculum Framework. Behavior Analysis in Practice, 12(1), 235-246. doi:10.1007/s40617-018-0236-X

Silverman, D. (2016). Qualitative research. London: SAGE Publications.

Smith, D. P., Hayward, D. W., Gale, C. M., Eikeseth, S., \& Klintwall, L. (2019). Treatment gains from early and intensive behavioral intervention (EIBI) are maintained 10 years later. Behavior Modification, O(0), 1-12. doi:10.1177/0145445519882895

Smith, T. (2001). Discrete trial training in the treatment of autism. Focus on Autism and Other Developmental Disabilities, 16(2), 86-92. doi:10.1177/108835760101600204

Smith, T., Eikeseth, S., Klevstrand, M., \& Lovaas, O. I. (1997). Intensive behavioral treatment for preschoolers with severe mental retardation and pervasive developmental disorder. American Journal on Mental Retardation, 102(3), 238-249.

Stake, R. E. (1995). The art of case study research (1 ed.). London: SAGE Publications.

Su, X., Guo, J., \& Wang, X. (2020). Different stakeholders' perspectives on inclusive education in China: parents of children with ASD, parents of typically developing children, and classroom teachers. International Journal of Inclusive Education, 24(9), 948-963. doi:10.1080/13603116.2018.1502367

Sun, X., Allison, C., Auyeung, B., Matthews, F. E., Baron-Cohen, S., \& Brayne, C. (2013). Service provision for autism in mainland China: Preliminary mapping of service pathways. Social Science \& Medicine, 98, 87-94.

Sun, X., Allison, C., Wei, L., Matthews, F. E., Auyeung, B., Wu, Y. Y., . . Brayne, C. (2019). Autism prevalence in China is comparable to Western prevalence. Molecular Autism, 10(1), 7. doi:10.1186/s13229-018-0246-0 
Running head: EIBI IN UK AND CHINA

Tao, K. T. (1987). Brief report: Infantile autism in China. Journal of Autism and Developmental Disorders, 17(2), 289-296. doi:10.1007/BF01495062

Taubman, M. T., Leaf, R. B., McEachin, J. J., Papovich, S., \& Leaf, J. B. (2013). A comparison of data collection techniques used with discrete trial teaching. Research in Autism Spectrum Disorders, 7(9), 1026-1034. doi:10.1016/j.rasd.2013.05.002

Tianjin city Disabled Federation. (2013). Prevention and rehabilitation of mental disorder. [精神病防止与康复]. Retrieved from http://www.tjdpf.org.cn/yw/kf/jsbfzykf/

Tseng, W., \& Wu, D. Y. H. (2013). Chinese culture and mental health. Orlando: Academic Press.

United States Surgeon General. (1999). Mental health: A report of the surgeon general. Retrieved from https://www.loc.gov/item/2002495357/

Wang, B., \& Kang, Y. S. (2011). Research review of early intensive behavior intervention. [自闭症儿童早期集中行为干预研究综述]. Journal of Educational Development, $12,52-55$.

Wang, H. (2011). An overview of the researchers into the educational rehabilitation of autistic children in China over the past few years and a regional comparison of the researchers. [近年中国孤独症儿童教育康复研究的整体情况与区域性比较]. Chinese Journal of Special Education, 4(130), 53-59.

Wang, J., Gu, S., Ye, B., Gao, J., Wang, F., Dai, J., \& Fu, H. (2019). The effect of migration and the hukou registration system on psychosocial domains and family functioning of children in Shanghai, China. International Health, 11(Supplement_1), S24-S32. doi:10.1093/inthealth/ihz076

Wang, K., Wang, C., Guo, D., van Wijngaarden, M., \& Begeer, S. . (2018). Children with autism spectrum disorder from China and the Netherlands: Age of diagnosis, gender and comorbidities. Research in Autism Spectrum Disorders, 54, 76-82. doi:https://doi.org/10.1016/j.rasd.2018.07.004

Warren, Z., McPheeters, M. L., Sathe, N., Foss-Feig, J. H., Glasser, A., \& VeenstraVanderWeele, J. (2011). A systematic review of early intensive intervention for autism spectrum disorders. Pediatrics, 127(5), e1303-e1311.

Welsh Government. (2009). The Autistic Spectrum Disorder (ASD) Strategic Action Plan for Wales. Retrieved from http://www.wales.nhs.uk/documents/ASD-strategy.pdf

Wolff, S. (2004). The history of autism. European Child \& Adolescent Psychiatry, 13(4), 201-208.

World Health Organization. (2019). Autism spectrum disorders. Retrieved from https://www.who.int/news-room/fact-sheets/detail/autism-spectrum-disorders

Yates, S. (2003). Doing social science research. London: SAGE Publications. 
Running head: EIBI IN UK AND CHINA

Zhou, H., Xu, X., Yan, W., Zou, X., Wu, L., Luo, X., . . . Team, L.-N. S. (2020). Prevalence of autism spectrum disorder in China: A nationwide multi-center population-based study among children aged 6 to 12 years. Neuroscience Bulletin. doi:10.1007/s12264020-00530-6

Zhu, J., Hua, Y., \& Yuan, C. (2020). Effects of remote performance feedback on procedural integrity of early intensive behavioral intervention programs in China. Journal of Behavioral Education, 29(2), 339-353. 